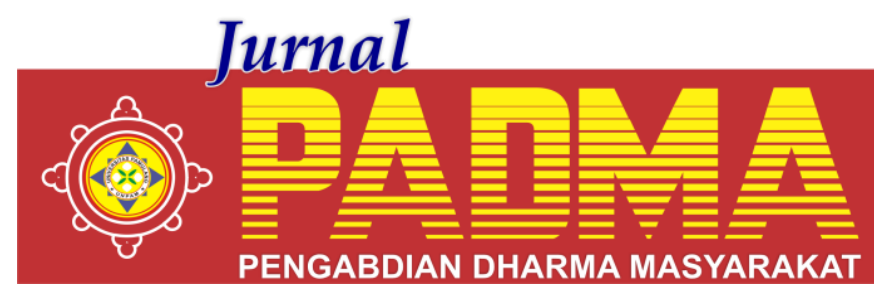

VOLUME 1, NOMOR 3, JULI 2021

\title{
PENYULUHAN MANAJEMEN SDM UNTUK PENGEMBANGAN KARAKTER REMAJA MASJID AT-TAQWA
}

\author{
${ }^{1}$ Ade Maulana, ${ }^{2}$ Adi Firmansyah, ${ }^{3}$ Fajar Syachril, ${ }^{4}$ Fanni Pratama, \\ ${ }^{5}$ Rahmat Ikhasni, ${ }^{6 *}$ Aidil Amin Effendy \\ Universitas Pamulang, Tangerang Selatan, Banten, Indonesia \\ *aidil00967@unpam.ac.id
}

\begin{abstract}
Abstrak
Kegiatan ini untuk mengetahui pelaksanaan kegiatan PKM sebagai wahana untuk membentuk jiwa kepemimpinan kepada siswa. Pengabdian kepada masyarakat ini menggunakan metode ceramah dan berdiskusi bersama siswa-siswi yang hadir Pelaksanaan kegiatan pengabdian kepada masyarakat dengan judul penyuluhan manajemen sumber daya manusia untuk pengembangan remaja masjid at-taqwa Sebanyak 25 remaja masjid mengikuti kegiatan ini namun belum mempunyai ilmu manajemen sdm yang baik. Hasil dari permasalahan diskusi ini adalah menciptakan manusia yang berkualitas sesuai dengan kompetensi atau keahliannya. Oleh sebab itu, dengan adanya manajemen SDM diharapkan remaja masjid akan mampu memberikan manfaat pada diri sendiri dan organisasinya.
\end{abstract}

Kata Kunci: Manajemen Sumber Daya Manusia Dalam Organisasi

Abstract

This activity is to know the implementation of PKM activities as a vehicle to form a leadership spirit to students. Community service uses the method of lectures and discussions with students who attend the implementation of community service activities with the title of human resource management counseling for the development of youth mosques at-taqwa As many as 25 mosque youth follow this activity but do not have good human resources management knowledge. The result of this discussion problem is to create a qualified human being in accordance with his competence or expertise. Therefore, with the management of human resources, it is expected that the youth of the mosque will be able to provide benefits to themselves and their organization.

Keywords: Human Resource Management In Organization

\section{PENDAHULUAN}

Ada empat landasan untuk mengembangkan manajemen menurut pandangan Islam, yaitu: Kebenaran, kejujuran, keterbukaan, keahlian. Seorang manajer harus memiliki empat sifat utama itu agar manajemen yang dijalankannya mendapatkan hasil yang maksimal. Yang paling penting dalam manajemen berdasarkan pandangan Islam adalah harus ada jiwa kepemimpinan. Kepemimpinan menurut Islam merupakan faktor utama dalam konsep manajemen.

Manajemen menurut pandangan Islam merupakan manajemen yang adil. Batasan adil adalah pemimpin tidak menganiaya bawahan dan bawahan tidak merugikan pemimpin maupun perusahaan yang ditempati. Bentuk penganiayaan yang dimaksudkan adalah mengurangi atau tidak memberikan hak bawahan dan memaksa bawahan untuk bekerja melebihi ketentuan. Seyogyanya kesepakatan kerja dibuat untuk kepentingan bersama antara pimpinan dan bawahan. Jika seorang manajer mengharuskan bawahannya bekerja melampaui waktu kerja yang ditentukan, maka sebenarnya manajer itu telah mendzalimi bawahannya. Dan ini sangat bertentangan dengan ajaran Islam menekankan pentingnya unsur kejujuran dan kepercayaan dalam manajemen Islam. Nabi Muhammad SAW adalah orang yang sangat terpercaya dalam menjalankan manajemen bisnisnya. Manajemen yang dicontohkan Nabi Muhammad SAW mengelola (manage) dan mempertahankan (mantain) kerjasama dengan stafnya dalam waktu yang lama dan bukan hanya hubungan sesaat. Salah satu kebiasaan Nabi adalah 
memberikan reward atas kreatifitas dan prestasi yang ditunjukkan stafnya.

\section{METODE}

1. Metode yang digunakan dalam pengabdian ini adalah metode ceramah dan berdiskusi bersama remaja masjid yaitu menjelaskan materi menggukan penggunaan pendekatan dengan secara virtual yang ada di rumah masing masing. Ada empat landasan untuk mengembangkan manajemen menurut pandangan Islam, yaitu: Kebenaran, kejujuran, keterbukaan, keahlian. Seorang manajer harus memiliki empat sifat utama itu agar manajemen yang dijalankannya mendapatkan hasil yang maksimal.

2. Organisasi akan berjalan baik dengan mempunyai visi misi yang baik karena di dalam visi misi mengetahui tujuan dari organisasi tersebut dan juga membuat struktur yang terarah dengan ini bisa melihat pembagian pembagian pekerjaan dengan jelas dan membangun komunikasi yang baik.

3. Pengertian manajemen yang paling sederhana adalah seni memperoleh hasil melalui berbagai kegiatan yangdilakukan oleh orang lain. Secara ringkas pengertian manajemen yaitu koordinasi semua sumber daya melalui proses perencanaan, pengorganisasian, penetapan tenaga kerja, pengarahan, dan pengawasan untuk mencapai tujuan yang telah ditetapkan terlebih dahulu.

4. Manajemen dalam Islam merupakan kegiatan, proses dan prosedur tertentu untuk mencapai tujuan akhir secara maksimal dengan bekerja sama sesuai jobnya masing-masing. Maka kebersamaan dan tujuan akhirlah yang menjadi fokus utama.

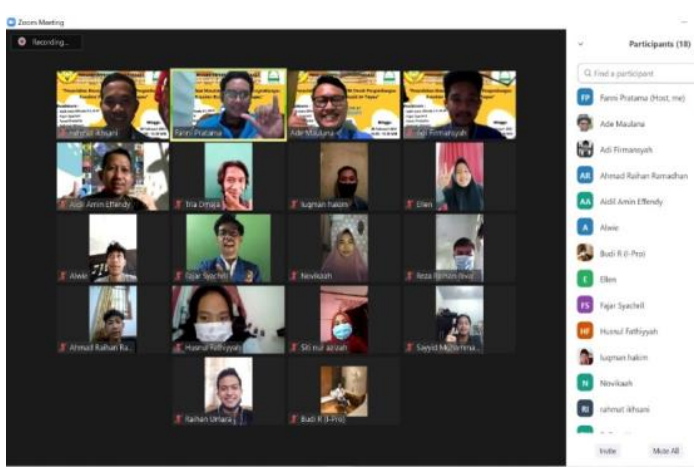

Gambar 1. Tim PKM sedan

Kegiatan ini diadakan pada tanggal 28 Februari 2021 kepada Remaja Masjid AtTaqwa melalui Video Conference Aplikasi Zoom.

\section{HASIL DAN PEMBAHASAN}

Adanya kegiatan pengabdian pada masyarakat yang dilakukan oleh tim PKM Mahasiswa/I Prodi Manajemen Universitas Pamulang, pelaksaann kegiatan PKM sebagai wahana untuk memahami ilmu Manajemen SDM kepada Remaja Masjid At-Taqwa atau yang lainnya. Disimpulkan bahwa Remaja Masjid At-Taqwa sangat berperan sebagai sarana dan wadah untuk memahami ilmu Manajemen SDM yang memiliki jiwa Enterpreuner. Ini terbukti dengan adanya PKM ini sebagai bentuk penyuluhan mengenai ilmu Manajemen SDM remaja Masjid At-Taqwa dalam berorganisasi. Proses yang dimaksud dalam penyuluhan

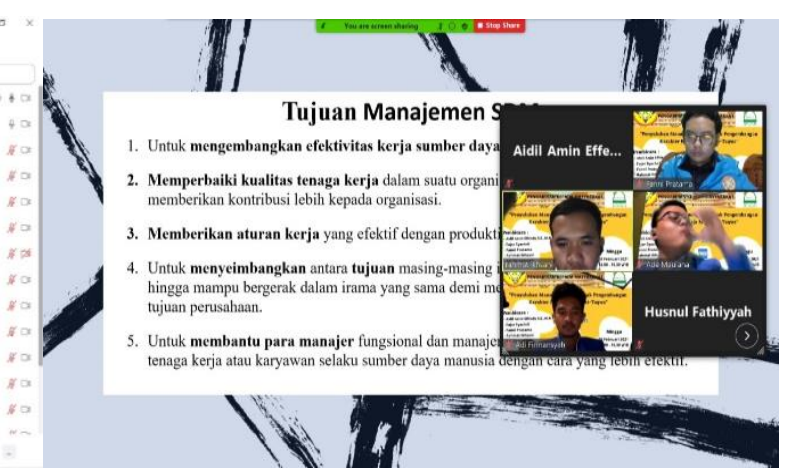

memberikan materi presentasi mengenai ilmu Manajemen SDM untuk memahami ilmu Manajemen SDM dalam organisasi. Seorang dikatakan memiliki jiwa kepemimpinan apabila seorang tersebut dapat memimpin anggotanya dengan baik, dapat bertanggung jawab terhadap tugas dan kewajibannya sebagai pemimpin, jujur, dapat menyampaikan didepan umum dengan baik, cerdas dan amanah.

\section{PENUTUP}

Sumber daya manusia merupakan kekuatan terbesar dalam pengolahan seluruh resources yang ada dimuka bumi, karena pada dasarnya seluruh ciptaan Allah yang ada dimuka bumi ini sengaja diciptakan oleh Allah untuk kemaslahatan umat manusia .Oleh karena itu sumber daya yang ada ini harus dikelola dengan benar karena itu merupakan amanah yang akan diminta pertanggungjawabannya kelak. Untuk 
mendapatkan pengelolaan yang baik ilmu sangatlah diperlukan untuk menopang pemberdayaan dan optimalisasi manfaat sunber daya yang ada. Di dalam surah ArRohman ayat ke 33, Allah telah menganjurkan manusia untuk menuntut ilmu seluas-luasnya tanpa batas dalam rangka membuktikan kemahakuasaan Allah SWT.

\section{DAFTAR PUSTAKA}

Ernawan, Erni R."Budaya Organisasi dalam Perspektif Ekonomi dan Bisnis. Bandung:Alfabeta (2011).

Hasibuan S.P Malayu. "Manajemen Sumber Daya Manusia. Jakarta: Bumi Aksara." (2014)

Hasibuan, Malayu S.P, "Manajemen Sumber Daya Manusia". Jakarta: PT Bumi Askara. ( 2011)

http://ejournal.radenintan.ac.id/index.php/i jtimaiyya/article/download/3414/22 95 (Diakses pada tanggal 15 Februari 2021)

https://adieenilmu.blogspot.com/2011/05/ manajemen-sumber-daya-manusiamsdm.html (Diakses pada tanggal 15 Februari 2021)Nurjaya, N., Sunarsi, D.,
Effendy, A. A., Teriyan, A., \& Gunartin, G. (2021). Pengaruh Etos Kerja Dan Disiplin Kerja Terhadap Kinerja Pegawai Pada Dinas Kehutanan Dan Perkebunan Kota Bogor. JENIUS (Jurnal Ilmiah Manajemen Sumber Daya Manusia), 4(2), 172-184.

https://id.wikipedia.org/wiki/Organisasi (Diakses pada tanggal 15 Februari 2021)

https://www.karyaone.co.id/blog/manajem en-sumber-daya-manusia/ (Diakses pada tanggal 15 Februari 2021)

Pangestu.1998. Statistik Induktif. Edisi IV. Yogyakarta: BPFE.Engel, et al. 2000. Perilaku Konsumen. Terj.F.X. Budianto. Jakarta : Binarupa Aksara.

Robbin \& Judge." Perilaku Organisasi Edisi 16. Jakarta. Salemba Empat." (2015 )

Sunarsi, D., Akbar, I. R., Rozi, A., Khoiri, A., \& Salam, R. (2021). The Influence of Motivation and Work Discipline on Employee Performance at the Yogyakarta Tourism Service. Prosiding ICoGEMT, 1(1), 1-7.

Ulber, Silalahi." Asas Asas Manajemen. Bandung: Refika Adit" (2011). 